\title{
Correlation of Pathological Complete Response With Tumor Volume Reduction During Neoadjuvant Chemoradiotherapy in Lung Cancer
}

\author{
SHIGEO TAKAHASHI ${ }^{1}$, TETSUHIKO GO ${ }^{2}$, MASAHIDE ANADA ${ }^{1}$, TOSHIFUMI KINOSHITA ${ }^{1}$, \\ TAKAMASA NISHIDE ${ }^{1}$, HIROYASU YOKOMISE ${ }^{2}$ and TORU SHIBATA ${ }^{1}$ \\ ${ }^{1}$ Department of Radiation Oncology, Kagawa University Hospital, Kagawa, Japan; \\ ${ }^{2}$ Department of General Thoracic, Breast and Endocrine Surgery, \\ Faculty of Medicine, Kagawa University, Kagawa, Japan
}

\begin{abstract}
Background/Aim: We retrospectively investigated the relationship between pathological complete response ( $p C R)$ and tumor volume (TV) reduction during neoadjuvant chemoradiation therapy (NACRT) in non-small cell lung cancer (NSCLC). Patients and Methods: We evaluated patients who received NACRT (50 Gy/25 fractions with platinum-doublet) plus surgery for NSCLC. TVs before and during NACRT $\left(T V_{\text {before }}\right.$ and $T V_{\text {during, }}$, respectively) were measured based on the sums of the volumes of primary tumors and clinically positive lymph nodes. Relative change in TV was computed as $\%\left(T V_{\text {during }}-T V_{\text {before }}\right) / T V_{\text {before }}$. Results: In total, 31 patients were analyzed. The median of the relative change in $T V$ was $49 \%$ and ranged from -83 to $-10 \%$. Postoperatively, $p C R$ was achieved in 11 patients (35\%). In multivariate analysis, the relative change in $T V$ was found to be an independent predictor of $p C R(p=0.003)$. Conclusion: TV reduction during NACRT appears to be associated with $p C R$ in NSCLC.
\end{abstract}

Neoadjuvant chemoradiation therapy (NACRT) plus surgery in patients with non-small cell lung cancer (NSCLC) is recommended for potentially resectable superior sulcus tumors and is described as an option for single-station N2 disease (1). A study showed that tumor volume (TV) reduction after NACRT is associated with pathological complete response (pCR) in NSCLC (2). We consider that

This article is freely accessible online.

Correspondence to: Shigeo Takahashi, MD, Ph.D., Department of Radiation Oncology, Kagawa University Hospital, 1750-1 Ikenobe, Miki-cho, Kita-gun, Kagawa 761-0793, Japan. Tel: +81 878985111, Fax: +81 878912427, e-mail: shigeot@med.kagawa-u.ac.jp

Key Words: Tumor volume, radiochemotherapy, pathologic complete response. the prediction of pCR during NACRT may be useful in making clinical decisions. For example, in patients with little expectation of pCR, we can complete the planned NACRT so that to achieve locoregional cure via surgery. Furthermore, if patients with every expectation of pCR have some possibilities of inoperability, we may switch the treatment strategy from NACRT to definitive CRT without delay. Therefore, we examined the relationship between pCR and TV reduction during NACRT in NSCLC.

\section{Patients and Methods}

Eligibility criteria. The Institution's ethics committee approved this retrospective study under the number H29-207. Eligibility criteria of this study were as follows: 1) patients underwent NACRT plus surgery from 2007 to 2017 ; 2) NACRT was performed using 50 Gy/25 fractions and platinum-doublet chemotherapy; and 3) before and during NACRT, contrast-enhanced computed tomography (CECT) was performed.

Treatment. Details of the treatment procedure of NACRT followed by surgery has been previously described (3). Briefly, the volumes of primary tumors and the clinically positive lymph nodes (LNs) diagnosed using CECT and fluorodeoxyglucose-positron emission tomography were defined as gross tumor volumes (GTVs). Clinical target volume (CTV) was defined as the GTV with 5-10 mm margin and the nodal station to which the clinically positive LNs belong. Planning target volume was defined as the CTV with 5-10 mm margin. Prescribed dose at the isocenter of conventionally fractionated three-dimensional conformal RT was $50 \mathrm{~Gy} / 25$ fractions using a 6-MV photon beam by a linear accelerator.

Concurrent chemotherapy was performed. Platinum-doublet regimens were selected at the physician's discretion, on the basis of our single Institutional prospective trials $(4,5)$.

Patients underwent surgery by open thoracotomy approx. 1-2 months after NACRT. Wrapping of bronchial stumps was performed using the intercostal muscle flap or pedicle fat pad.

Evaluation. As reported in a previous study (2), using MIM Maestro ver. 6.4 (MIM Software, Cleveland), TVs before and during NACRT ( $\mathrm{TV}_{\text {before }}$ and $\mathrm{TV}_{\text {during }}$, respectively) were measured using 
sums of the volumes of primary tumors and clinically positive lymph nodes on CECT images before and during NACRT, respectively. Relative change in the TV was computed as \% $\left(\mathrm{TV}_{\text {during }}-\mathrm{TV}_{\text {before }}\right) / \mathrm{TV}_{\text {before }}$. A pCR was defined as no evidence of residual viable tumor cells based on the surgical pathology report.

Statistics. Factors for pCR were assessed by univariate analyses using Fisher's exact or Wilcoxon rank-sum tests and by multivariate analyses using the multiple logistic regression test. Statistical significance was defined as a $p$-value $<0.05$. JMP ver. 11 (SAS Institute, Cary, NC, USA) was used for statistical analyses.

\section{Results}

A total of 31 patients met the eligibility criteria, and their characteristics are presented in Table I. CECT during NACRT was performed at a median dose of $40 \mathrm{~Gy}$ and ranged from 24 to $50 \mathrm{~Gy}$. The median of the relative change in the TV was $-49 \%$ and ranged from -83 to $-10 \%$. Postoperatively, pCR was achieved in 11 patients $(35 \%)$. A waterfall plot of the relative change in TV is shown in Figure 1.

Univariate and multivariate analyses of the factors for pCR are presented in Table II. The relative change in TV was an independent predictor of $\mathrm{pCR}$ in the multivariate analysis $(p=0.003)$.

Cutoff value of the relative change in the TV for pCR was $-64 \%$, which was calculated using a receiver operating characteristic curve (area under the curve $=0.841$ ): pCR was achieved in 8 of 9 patients $(89 \%)$, whose tumors shrunk more than this cutoff value.

\section{Discussion}

This is the first study to examine the relationship between pCR and TV reduction during NACRT in NSCLC.

A previous study has shown that TV reduction after NACRT is more associated with pCR than with conventional response assessment using the Response Evaluation Criteria in Solid Tumors (2). In the study, TV reduction was assessed at the median time of 18 days after completion of NACRT (2). We agree that the timing is reasonable for restaging toward surgery to confirm the absence of distant metastasis. However, if the locoregional disease is judged to be inoperable at restaging 18 days after the last irradiation, adding RT up to the dose of definitive CRT is difficult, because the interval will decrease the treatment effect due to prolonged overall treatment time $(6,7)$. In contrast, if we are able to predict pCR during NACRT, the information may aid clinical decisions regardless of the expectations of $\mathrm{pCR}$. For example, in patients with little expectation of pCR, we can complete the scheduled NACRT to obtain locoregional control by salvage surgery. Moreover, in patients with every expectation of a $\mathrm{pCR}$, if they are judged as inoperable (8-10), we may change from NACRT to definitive CRT immediately.
Table I. Characteristics of patients and tumors.

\begin{tabular}{|c|c|c|c|}
\hline & Number & $\%$ & Median (range) \\
\hline Age (years) & & & $64(49-78)$ \\
\hline \multicolumn{4}{|l|}{ Gender } \\
\hline Male & 26 & 84 & \\
\hline Female & 5 & 16 & \\
\hline \multicolumn{4}{|l|}{ Histology } \\
\hline Squamous cell carcinoma & 16 & 52 & \\
\hline Adenocarcinoma & 13 & 42 & \\
\hline Adenosquamous cell carcinoma & 1 & 3 & \\
\hline Carcinosarcoma & 1 & 3 & \\
\hline \multicolumn{4}{|l|}{ cT-status* } \\
\hline 1 & 4 & 13 & \\
\hline 2 & 9 & 29 & \\
\hline 3 & 13 & 42 & \\
\hline 4 & 5 & 16 & \\
\hline \multicolumn{4}{|l|}{ cN-status* } \\
\hline 0 & 2 & 6 & \\
\hline 1 & 11 & 36 & \\
\hline 2 & 16 & 52 & \\
\hline 3 & 2 & 6 & \\
\hline \multicolumn{4}{|l|}{ c-Stage* } \\
\hline IIA & 2 & 6 & \\
\hline IIB & 1 & 3 & \\
\hline IIIA & 26 & 85 & \\
\hline IIIB & 2 & 6 & \\
\hline \multicolumn{4}{|l|}{ Chemotherapy } \\
\hline Carboplatin + docetaxel & 18 & 59 & \\
\hline Carboplatin + pemetrexed & 4 & 13 & \\
\hline Cisplatin + docetaxel & 3 & 10 & \\
\hline Cisplatin + S-1 & 2 & 6 & \\
\hline Carboplatin $+\mathrm{S}-1$ & 2 & 6 & \\
\hline Cisplatin + pemetrexed & 1 & 3 & \\
\hline Carboplatin + paclitaxel & 1 & 3 & \\
\hline $\begin{array}{l}\text { RT dose at CECT } \\
\text { during NACRT (Gy) }\end{array}$ & & & $40(24-50)$ \\
\hline $\mathrm{TV}_{\text {before }}(\mathrm{ml})$ & & & $45.1(11.4-584.2)$ \\
\hline $\mathrm{TV}_{\text {during }}(\mathrm{ml})$ & & & $27.0(5.9-195.0)$ \\
\hline Relative change in the TV $(\%)^{* *}$ & & & $-49(-83$ to -10$)$ \\
\hline $\begin{array}{l}\text { Interval from completion of } \\
\text { NACRT to surgery (weeks) }\end{array}$ & & & $7(3-19)$ \\
\hline
\end{tabular}

*Based on $7^{\text {th }}$ edition of the Union for International Cancer Control. **Relative change in the TV was computed as \% $\left(\mathrm{TV}_{\text {during }}\right.$ $\left.\mathrm{TV}_{\text {before }}\right) / \mathrm{TV}_{\text {before }}$ RT: Radiation therapy; CECT: contrast enhanced computed tomography; NACRT: neoadjuvant chemoradiation therapy; TV: tumor volume; $\mathrm{TV}_{\text {before }}$ TVs before NACRT; $\mathrm{TV}_{\text {during }}$ : TVsduring NACRT.

Our study has some limitations such as the small number of events and its retrospective single institutional design.

In conclusion, TV reduction during NACRT appears to be associated with pCR in NSCLC. The cutoff value of $-64 \%$ in the relative change in TV during NACRT may be a prognostic factor of pCR.

\section{Conflicts of Interest}

The Authors have no conflicts of interest regarding this study. 


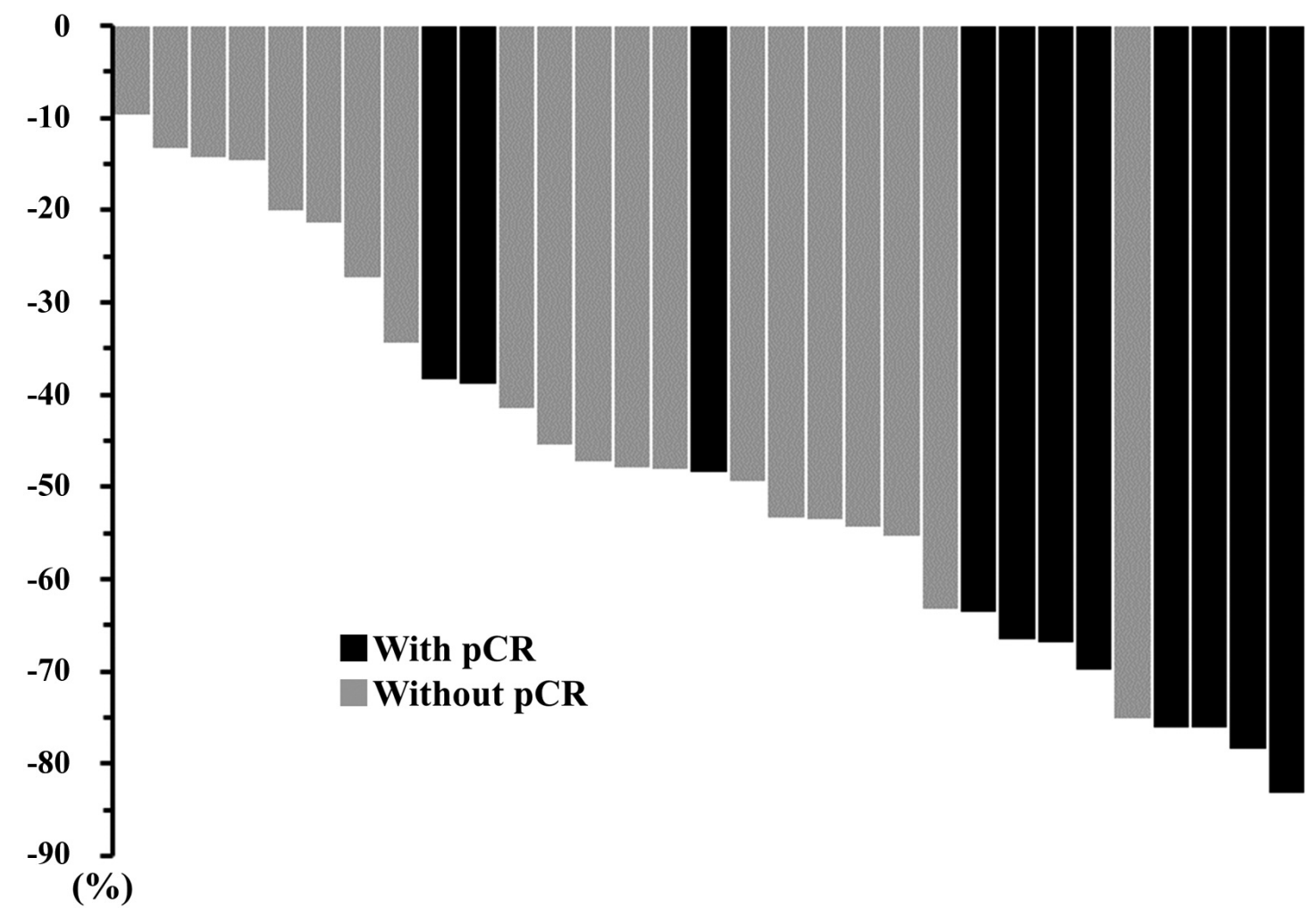

Figure 1. Waterfall plot of relative change in tumor volume. Black and gray bars indicate patients with and without pathological complete response $(p C R)$, respectively.

Table II. Uni/multivariate analyses for the factors affecting $p C R$.

\begin{tabular}{|c|c|c|c|c|c|}
\hline & & $\mathrm{pCR}$ rate & Median (range) & $\begin{array}{l}\text { Univariate } \\
p \text {-Value }\end{array}$ & $\begin{array}{c}\text { Multivariate } \\
p \text {-Value }\end{array}$ \\
\hline Age (years) & With pCR & & $\begin{array}{l}63(49-77) \\
64(51-78)\end{array}$ & 0.725 & - \\
\hline Gender & $\begin{array}{l}\text { Male } \\
\text { Female }\end{array}$ & $\begin{array}{c}10 / 26(38 \%) \\
1 / 5(20 \%)\end{array}$ & & 0.631 & - \\
\hline Histology & $\begin{array}{l}\text { Sq } \\
\text { Others }\end{array}$ & $\begin{array}{l}7 / 16(44 \%) \\
4 / 15(27 \%)\end{array}$ & & 0.458 & - \\
\hline cT-status* & $\begin{array}{l}1-2 \\
3-4\end{array}$ & $\begin{array}{l}6 / 13(46 \%) \\
5 / 18(28 \%)\end{array}$ & & 0.449 & - \\
\hline cN-status* & $\begin{array}{l}0-1 \\
2-3\end{array}$ & $\begin{array}{l}5 / 13(38 \%) \\
6 / 18(33 \%)\end{array}$ & & 1.000 & - \\
\hline Chemotherapy & $\begin{array}{l}\text { With taxane } \\
\text { Without taxane }\end{array}$ & $\begin{array}{c}10 / 22(45 \%) \\
1 / 9(11 \%)\end{array}$ & & 0.107 & - \\
\hline RT dose at CECT during NACRT (Gy) & $\begin{array}{l}\text { With pCR } \\
\text { Without pCR }\end{array}$ & & $\begin{array}{l}42(30-50) \\
40(24-50)\end{array}$ & 0.561 & - \\
\hline $\mathrm{TV}_{\text {before }}(\mathrm{cc})$ & $\begin{array}{l}\text { With pCR } \\
\text { Without pCR }\end{array}$ & & $\begin{array}{l}87.2(27.5-584.2) \\
41.8(11.4-128.2)\end{array}$ & 0.039 & 0.157 \\
\hline $\mathrm{TV}_{\text {during }}(\mathrm{cc})$ & $\begin{array}{l}\text { With pCR } \\
\text { Without pCR }\end{array}$ & & $\begin{array}{c}27.0(5.9-195.0) \\
28.0(5.9-62.9)\end{array}$ & 0.984 & - \\
\hline Relative change in the TV $(\%)^{* *}$ & $\begin{array}{l}\text { With pCR } \\
\text { Without pCR }\end{array}$ & & $\begin{array}{l}-67(-83 \text { to }-39) \\
-47(-75 \text { to }-10)\end{array}$ & 0.002 & 0.003 \\
\hline
\end{tabular}

*Based on $7^{\text {th }}$ edition of the Union for International Cancer Control. **Relative change in the $\mathrm{TV}$ was computed as $\%\left(\mathrm{TV}_{\text {during }}-\mathrm{TV}_{\text {before }}\right) / \mathrm{TV}_{\text {before }}$. pCR: Pathological complete response; Sq: squamous cell carcinoma; RT: radiation therapy; CECT: contrast enhanced computed tomography; NACRT: neoadjuvant chemoradiation therapy; TV: tumor volume; $\mathrm{TV}_{\text {before }}$ TVs before NACRT; $\mathrm{TV}_{\mathrm{during}}$ : $\mathrm{TV}$ s during NACRT. 


\section{Authors' Contributions}

This study was coordinated by ST and TG. Data were collected by ST, MA, TK, and TN. Collected data was analysed by ST. This article was drafted by ST. Data interpretation and article revision were performed by all authors: ST, TG, MA, TK, TN, HY, and TS. All Authors approved the publication of this article.

\section{Acknowledgements}

This work was partly supported by JSPS KAKENHI Grant Numbers 15K19798 and 20K16790.

\section{References}

1 Postmus PE, Kerr KM, Oudkerk M, Senan S, Waller DA, Vansteenkiste J, Escriu C and Peters S: Early and locally advanced non-small-cell lung cancer (NSCLC): ESMO Clinical Practice Guidelines for diagnosis, treatment and follow-up. Ann Oncol 28(suppl_4): iv1-iv21, 2017. PMID: 28881918. DOI: 10.1093/annonc/mdx222

2 Agrawal V, Coroller TP, Hou Y, Lee SW, Romano JL, Baldini EH, Chen AB, Jackman DM, Kozono D, Swanson SJ, Wee JO, Aerts HJ and Mak RH: Radiologic-pathologic correlation of response to chemoradiation in resectable locally advanced NSCLC. Lung Cancer 102: 1-8, 2016. PMID: 27987576. DOI: 10.1016/j.lungcan.2016.10.002

3 Takahashi S, Go T, Kasai Y, Yokomise H and Shibata T: Relationship between dose-volume parameters and pulmonary complications after neoadjuvant chemoradiotherapy followed by surgery for lung cancer. Strahlenther Onkol 192(9): 658-667, 2016. PMID: 27418130. DOI: 10.1007/s00066-016-1021-9

4 Yokomise H, Gotoh M, Okamoto T, Yamamoto Y, Ishikawa S, Nakashima T, Masuya D, Liu D and Huang CL: Induction chemoradiotherapy (carboplatin-taxane and concurrent 50-Gy radiation) for bulky cN2, N3 non-small cell lung cancer. J Thorac Cardiovasc Surg 133(5): 1179-1185, 2007. PMID: 17467426. DOI: 10.1016/j.jtcvs.2006.12.039

5 Yokomise H, Liu D, Ishikawa S, Go T, Gotoh M, Okuda M, Tarumi S, Kasai Y and Matsuura N: Chemotherapy followed by surgery on the basis of biomarker examination for patients with advanced non-small cell lung cancer. Anticancer Res 33(12): 5597-5602, 2013. PMID: 24324104.
6 Chen M, Jiang GL, Fu XL, Wang LJ, Qian H, Chen GY, Zhao $\mathrm{S}$ and Liu TF: The impact of overall treatment time on outcomes in radiation therapy for non-small cell lung cancer. Lung Cancer 28(1): 11-19, 2000. PMID: 10704704. DOI: 10.1016/s01695002(99)00113-0

7 McMillan MT, Ojerholm E, Verma V, Higgins KA, Singhal S, Predina JD, Berman AT, Grover S, Robinson CG and Simone CB 2nd: Radiation treatment time and overall survival in locally advanced non-small cell lung cancer. Int J Radiat Oncol Biol Phys 98(5): 1142-1152, 2017. PMID: 28721898. DOI: 10.1016/j.ijrobp.2017.04.004

8 Fernandez FG, Kosinski AS, Burfeind W, Park B, DeCamp MM, Seder C, Marshall B, Magee MJ, Wright CD and Kozower BD: The Society of Thoracic Surgeons Lung Cancer Resection Risk Model: Higher Quality Data and Superior Outcomes. Ann Thorac Surg 102(2): 370-377, 2016. PMID: 27209606. DOI: 10.1016/j.athoracsur.2016.02.098

9 Brunelli A, Salati M, Rocco G, Varela G, Van Raemdonck D, Decaluwe $\mathrm{H}$ and Falcoz PE: European risk models for morbidity (EuroLung1) and mortality (EuroLung2) to predict outcome following anatomic lung resections: an analysis from the European Society of Thoracic Surgeons database. Eur J Cardiothorac Surg 51(3): 490-497, 2017. PMID: 27744321. DOI: $10.1093 /$ ejcts/ezw319

10 Endo S, Ikeda N, Kondo T, Nakajima J, Kondo H, Shimada Y, Sato M, Toyooka S, Okada Y, Sato Y, Yoshino I, Okada M, Okumura M, Chida M, Fukuchi E and Miyata H: Risk assessments for broncho-pleural fistula and respiratory failure after lung cancer surgery by National Clinical Database Japan. Gen Thorac Cardiovasc Surg 67(3): 297-305, 2019. PMID: 30328066. DOI: $10.1007 / \mathrm{s} 11748-018-1022-y$ 